Review

\title{
RNF20-SNF2H Pathway of Chromatin Relaxation in DNA Double-Strand Break Repair
}

\author{
Akihiro Kato * and Kenshi Komatsu \\ Division of Genome Repair Dynamics, Radiation Biology Center, Kyoto University, \\ Yoshida-konoecho, Sakyo-ku, Kyoto 606-8501, Japan; \\ E-Mail: komatsu@house.rbc.kyoto-u.ac.jp \\ * Author to whom correspondence should be addressed; E-Mail: akato@house.rbc.kyoto-u.ac.jp; \\ Tel.: +81-75-753-7567; Fax: +81-75-753-7564.
}

Academic Editor: Jessica Tyler

Received: 15 June 2015 / Accepted: 9 July 2015 / Published: 14 July 2015

\begin{abstract}
Rapid progress in the study on the association of histone modifications with chromatin remodeling factors has broadened our understanding of chromatin dynamics in DNA transactions. In DNA double-strand break (DSB) repair, the well-known mark of histones is the phosphorylation of the $\mathrm{H} 2 \mathrm{~A}$ variant, $\mathrm{H} 2 \mathrm{AX}$, which has been used as a surrogate marker of DSBs. The ubiquitylation of histone H2B by RNF20 E3 ligase was recently found to be a DNA damage-induced histone modification. This modification is required for DSB repair and regulated by a distinctive pathway from that of histone H2AX phosphorylation. Moreover, the connection between $\mathrm{H} 2 \mathrm{~B}$ ubiquitylation and the chromatin remodeling activity of SNF2H has been elucidated. In this review, we summarize the current knowledge of RNF20-mediated processes and the molecular link to H2AX-mediated processes during DSB repair.
\end{abstract}

Keywords: DNA double-strand break repair; ubiquitylation of histone H2B; RNF20; chromatin relaxation; SNF2H; KAP-1; CHD3.1

\section{Introduction}

In eukaryotes, DNA is packaged into condensed chromatin in the form of a nucleosome that consists of two copies of the core histones, $\mathrm{H} 2 \mathrm{~A}, \mathrm{H} 2 \mathrm{~B}, \mathrm{H} 3$ and $\mathrm{H} 4$. Thus, chromatin structures dynamically 
change to express or repress the genetic information stored in DNA during transcription. Recent studies have revealed that chromatin dynamics in transcription share the common molecular mechanisms in DNA transaction, such as DNA replication and DNA repair. The ubiquitylation of the histone H2B is known to be involved in chromatin dynamics during transcription and lately, a role was also shown in the initiation of homologous recombination through the alteration of the chromatin structure. This is corroborated by evidence that ubiquitylation promotes the accumulation of chromatin remodeling factor, $\mathrm{SNF} 2 \mathrm{H}$, in DNA repair, while it is known to have a decondensing activity during transcription. We first reported the relationship between $\mathrm{H} 2 \mathrm{~B}$ ubiquitylation and SNF2H in DNA repair in a previous study [1]; thereafter, accumulating evidence by other groups has deciphered the molecular aspects of histone modification in chromatin remodeling. In this article, we summarize the recent advances in understanding the molecular pathway of H2B ubiquitylation for DSB-induced chromatin remodeling.

\section{Ubiquitylation of Histone H2B}

Many post-translational modifications of core histones, including acetylation, methylation, phosphorylation, ubiquitylation, SUMOylation, ADP ribosylation, deimination, and proline isomerization, have been reported [2], while ubiquitylation is limited to the histones such as $\mathrm{H} 2 \mathrm{~A}$ and $\mathrm{H} 2 \mathrm{~B}$ [3-5]. Yeast histone H2B on lysine 123 (K123) is mono-ubiquitylated with ubiquitin-conjugating enzyme (E2) RAD6 and ubiquitin ligase (E3) BRE1 [6-8]. In mammalian cells, the heterodimeric complex of RNF20-RNF40, orthologues of yeast Bre1, mono-ubiquitylates lysine 120 (K120) of H2B in conjunction with its cognate E2 enzyme RAD6 [9-11]. It is noted that a heterodimer of two BRE1 paralogues is formed in fission yeast, whereas budding yeast forms a homodimer of single BRE1 [11-13]. Although histone H2B is mono-ubiquitylated by other E3 ligases such as BAF250B, Mdm2, BRCA1-BARD1, and MSL2 [14-16] and several other residues of $\mathrm{H} 2 \mathrm{~B}$, including $\mathrm{K} 34, \mathrm{~K} 46, \mathrm{~K} 108$, and $\mathrm{K} 116$, are also ubiquitylated [17], mammalian histone H2B at K120 is exclusively mono-ubiquitylated by the RNF20-RNF40 complex $[1,18]$. Moreover, the ubiquitins bound to $\mathrm{H} 2 \mathrm{~B}$ are reversibly removed by the deubiquitylating enzymes (DUBs) in cells. Currently, USP3, USP7, USP12, USP22, USP44, USP46, and USP49 in mammals [19-24] and Ubp8 and Ubp10 in yeast $[25,26]$ have been implicated as DUBs of ubiquitylated H2B.

Similar to the heterodimeric complexes of RNF20-RNF40, several homodimeric and heterodimeric complex formations have been reported in the RING (really interesting new gene) family of E3 ubiquitin ligase, including cIAP, RNF4, BIRC7, IDOL, CHIP, Prp19, BRCA1-BARD1, Mdm2-MdmX, and RING1B-Bmi1 [27]. The RING family of E3 ligases lose their bona fide catalytic center and alternatively, they promote the transfer of ubiquitin from cognate E2 enzyme to their substrates by the activation of the E2 enzyme [27,28]. The RING family of E3 ligase is generally believed to interact with the cognate E2 enzyme through their RING domains, suggesting a critical role of the RING domain in the ubiquitin ligase activity for the activation of E2 enzyme [27,28]. Conversely, the RING domain is also implicated in the formation of the homodimeric and heterodimeric complexes. Both RNF20 and RNF40, as members of the RING family of E3 ligase, have a RING finger domain at their C-terminus, and the RING domain of BRE1 is critical for the ubiquitin ligase activity, similar to other members of the RING family [11,13]. However, the RING domain is dispensable in the interaction with RAD6 cognate enzyme in both RNF20-RNF40 and yeast BRE1 [11,13]. In contrast, this domain is critical for the formation of a heterodimeric complex and stability of each protein [18]. Because the knockdown of either RNF20 or 
RNF40 induces the degradation of both proteins, their interaction through the RING domain is necessary for their protein stabilities and the resulting ubiquitin ligase activity.

H2B ubiquitylation has been reported in many cellular and biological processes, including DNA replication [29,30], DNA repair [1,18], nucleosome positioning [31], chromatin segregation [32], centromeric chromatin maintenance [33], chromatin boundary integrity [34], RNA processing and export [35-37], stem cell differentiation [23,38,39], development [40], exit from mitosis [41], apoptosis [42], tumorigenesis [43-45], and viral infection [46,47]. Among them, an accumulating number of reports indicate the strong relationship of $\mathrm{H} 2 \mathrm{~B}$ ubiquitylation with transcription activation $[5,45]$. A genome-wide analysis of $\mathrm{H} 2 \mathrm{~B}$ ubiquitylation using a chromatin immunoprecipitation technique revealed that $\mathrm{H} 2 \mathrm{~B}$ ubiquitylation is broadly associated with transcribed genes itself but not with the promoter region. This is consistent with the result from the reconstituted transcription assay in vitro, showing that transcription elongation is regulated by $\mathrm{H} 2 \mathrm{~B}$ ubiquitylation [48]. When RNA polymerase II halts at the nucleosome, the histone chaperone FACT (facilitates chromatin transcription) recruits both transcription elongation regulator PAF complex and RNF20/40 heterodimers, which is followed by H2B ubiquityaltion, resulting in the displacement of the histone $\mathrm{H} 2 \mathrm{~A} / \mathrm{H} 2 \mathrm{~B}$ dimer to traverse RNA polymerase II through the nucleosome. However, conflicting results for this model have also been reported. Microarray analysis using HeLa cells treated with RNAi revealed that only $6 \%$ of the genes were significantly affected by RNF20 depletion, in which approximately half of these were upregulated and the rest were downregulated [43]. This suggests that RNF20-mediated transcription regulation is not simple but rather complicated in cells.

\section{Chromatin Remodeling with SNF2H}

The proteins that regulate the packaging of DNA into chromatin, termed as chromatin remodeling factors, are involved in many cellular processes dealing with eukaryotic DNA, such as transcription, replication, and repair [49]. There are four ATP-dependent chromatin remodeling families, SWI/SNF, INO80, CHD, and ISWI, all of which are well-conserved through the species [49]. The human ISWI (imitation switch) family represents two kinds of ATPase, SNF2H (also known as SMARCA5) and SNF2L (also known as SMARCA1), which are the orthologues of yeast Isw1 and Isw2, respectively [50]. To date, seven ISWI complexes, including ACF, CHRAC, WICH, RSF, CERF, NoRC, and NURF [51], have been reported in mammals, and all of these have either employed SNF2H or SNF2L as a catalytic subunit of ATPase (Figure 1A). Among the ISWI complexes, ACF, CHRAC, WICH, and RSF containing SNF2H are implicated in DNA repair [52-56], while ACF and WICH also have roles in the maintenance of chromatin structures during DNA replication, where the depletion of SNF2H causes compacting of chromatin [57,58]. Chromatin remodeling factors often associate with histone marks for their localization at the chromatin. Plant homeodomain (PHD) fingers and chromodomains often exist in chromatin remodeling families, and interact with methyl-lysine and acetyl-lysine of histones, respectively [59,60]. Although SNF2H does not have these domains, it is plausible that SNF2H indirectly interacts with modified histones through other accessary subunits containing these domains. Indeed, TIP5, the binding partner of SNF2H in the NoRC complex, has a PHD finger and bromodomain within the structure, and they cooperatively interact with acetylated histone H4 Lys16 (H4K16ac) for rDNA silencing [61]. Similarly, BPTF, the subunit of SNF2L-containing NURF complex, interacts with H3K4me3 and 
H4K16ac by its PHD finger and bromodomain and recruits NURF complex to transcription sites for its chromatin remodeling [62-64]. In DSB repair, ACF1 has been implicated in recruiting SNF2H to DSB sites via an interaction between its PHD domain and trimethylated histone H3 at Lys9 (H3K9me3) (see below).

A
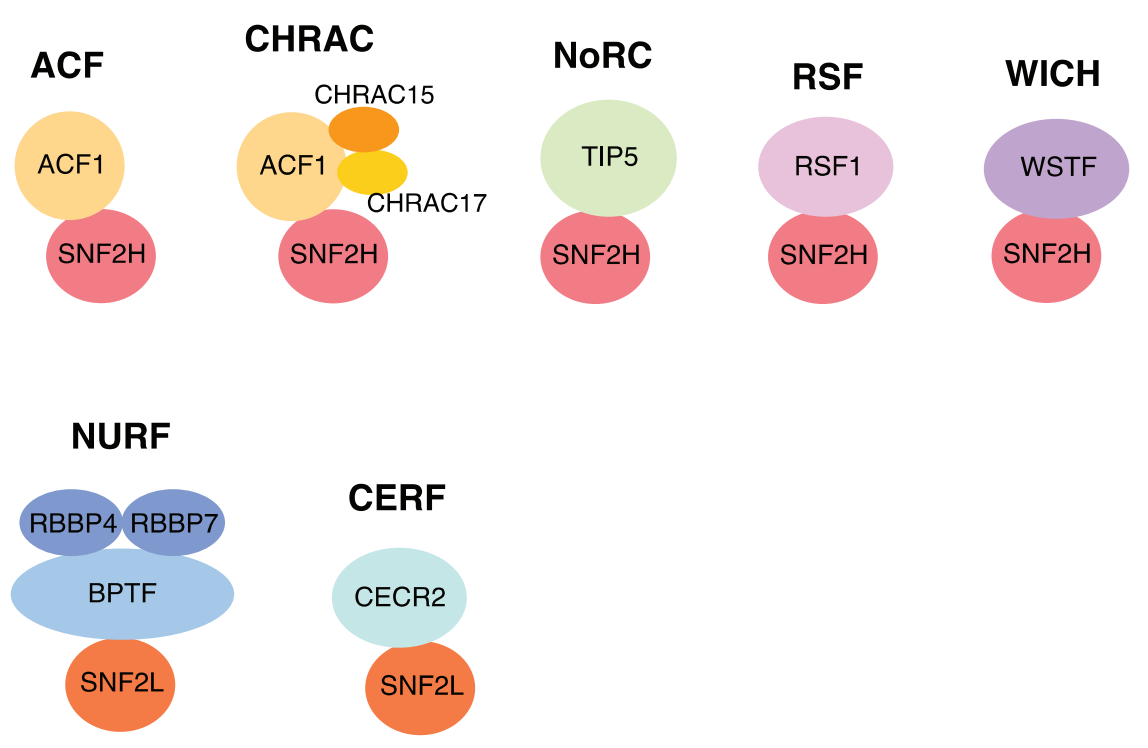

B

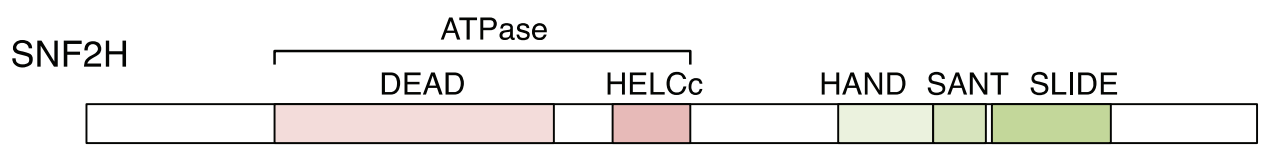

Figure 1. ISWI family of chromatin remodeling complexes in mammal: (A) Currently known seven complexes are shown. (B) Schematic representation of human SNF2H (sucrose nonfermenting 2 homolog). The ATPase domain is located at N-terminal half of SNF2H. The HSS domain composed of HAND, SANT (Swi3, Ada2, NCoR, TFIIB) and SLIDE (SANT-like ISWI domain) is located at C-terminus.

SNF2H contains an ATPase domain at the N-terminus, which is composed of two conserved regions, DExx and HELICc, termed the DEAD/H superfamily; hence, it can accomplish chromatin remodeling using the energy of ATP hydrolysis $[49,65,66]$. On the other hand, SNF2H represents the characteristic domains at the C-terminus, which consists of three domains, HAND, SANT (Swi3, Ada2, NCoR, TFIIB), and SLIDE (SANT-like ISWI), termed the HSS domain (Figure 1B). These domains play an important role in nucleosome spacing by binding to a histone tail and DNA [49]. In Drosophila ISWI, X-ray crystallography showed that the SANT domain interacts with histones, and the SLIDE domain binds to nucleosomal DNA [67]. Similarly, the HAND domain of yeast ISW2 interacts near the entry/exit site of the nucleosome, and the SLIDE domain associates with linker DNA [68]. The mutation experiments of the SANT-SLIDE domains suggest that they help to guide the movement of the linker DNA into the nucleosome for the directionality and efficiency of nucleosome sliding along DNA [69,70]. Thus, the ISWI family would achieve either chromosome relaxation or chromatin assembly by the nucleosome sliding activity and result in the optimized nucleosome spacing using the HSS domain at the C-terminus. 


\section{Molecular Link between H2B Ubiquitylation and SNF2H in DSB Repair}

Among the many types of DNA damage, DSBs are the most serious lesions. Although DSBs are generated during replication stress and genetic rearrangements of immunoglobulin and $\mathrm{T}$ cell receptor genes, ionizing radiation (IR) is known to efficiently elicit DSBs. Once DSBs are induced, they are detected by cellular machinery and rejoined by either of the two major repair pathways, homologous recombination (HR) repair and non-homologous end joining (NHEJ), so that cells can maintain genome integrity. A cellular response to IR occurs immediately after DSB generation because phosphorylation of the histone variant $\mathrm{H} 2 \mathrm{AX}$ (so-called $\gamma \mathrm{H} 2 \mathrm{AX}$ ) can be observed within seconds following IR exposure. ATM (Ataxia telangiectasia mutated) is a major regulatory kinase in DSB signal transduction [71] and phosphorylates more than 700 substrates [72], including H2AX. This ATM activation requires a protein complex consisting of MRE11, RAD50, and NBS1, termed the MRN complex [73,74]. The defect in NBS1 causes enhanced cell killing because of the impaired repair of HR and NHEJ and genomic instability after IR exposure [75,76].

The participation of H2B ubiquitylation in the DSB repair pathway was first implicated in yeast. Game et al. reported that a yeast bre1 mutant showed high sensitivity to IR and had epistatic interaction with rad51, the key molecule in HR [77]. This suggests that BRE1 functions in the RAD51-dependent HR repair of DSBs, although the molecular mechanisms in HR are largely unknown. Lately, Nakamura et al. and Moyal et al. independently reported that RNF20 interacts with NBS1 and ATM in human cells [1,18], indicating that $\mathrm{H} 2 \mathrm{~B}$ ubiquitylation is involved in NBS1-associated HR and NHEJ repair in human cells too. RNF20 interacts with the C-terminus of NBS1, in which several important domains for protein/protein interaction are located, while the binding site of ATM with RNF20-RNF40 has not yet been reported [1,78-80]. The depletion of RNF20 by RNAi resulted in high sensitivity to IR and DNA damaging agents such as neocarzinostatin (NCS), mitomycin C, and camptothecin [1,18,81]. Indeed, DSB repair kinetics, monitored by $\gamma \mathrm{H} 2 \mathrm{AX}$, became slower in RNF20-depleted cells. In addition, the genetic knockdown of RNF20 decreased the DSB repair when HR and NHEJ were quantitatively assayed using DR-GFP and pEJ reporter genes. Consistently, RNF20-depleted cells impaired the accumulation of HR factors such as BRCA1, RAD51, and RPA and NHEJ factors such as XRCC4 at the damage sites, exhibiting the roles of RNF20 in the recruitment of repair proteins to DSB sites [1,18,82]. Intriguingly, this RNF20-dependent accumulation of repair proteins requires ATM activation. Moyal et al. reported that S172/S553 of RNF20 and S114 of RNF40 are phosphorylated by ATM after DSB generation [18]. These phosphorylations are a pre-requisite of DSB-induced H2B ubiquitylation. The overexpression of the K120R H2B mutant, that lacks the lysine to be ubiquitylated, also significantly reduced HR frequency, accumulation of both HR and NHEJ proteins at the DSB sites, and the resulting enhancement of cell killing after IR exposure. Moreover, the concurrent depletion of RNF20 and overexpression of mutant H2B had no further effect, suggesting that RNF20 functions through a common pathway of DSB repair with that of $\mathrm{H} 2 \mathrm{~B}$ ubiquitylation.

The roles of RNF20 in the DSB repair pathway is considered to be associated with chromatin relaxation because the defects in the accumulation of the repair protein at the DSB sites were rescued by treatment with several agents that induce chromatin relaxation $[1,82]$. This is supported by a recent study, which shows that $\mathrm{H} 2 \mathrm{~B}$ ubiquitylation interferes with chromatin compacting and promotes chromatin accessibility [83]. Furthermore, the chromatin remodeling factor, SNF2H, functions as a downstream protein of RNF20. Because transcription studies have revealed that the ubiquitylation of $\mathrm{H} 2 \mathrm{~B}$ is followed 
by SNF2H accumulation, this molecule was a candidate for a factor involved in RNF20-dependent chromatin relaxation. Indeed, several groups reported that the knockdown of SNF2H resulted in similar phenotypes to that of RNF20-depleted cells, such as hypersensitivity to DNA damaging agents and IR, and impaired accumulation of HR and NHEJ proteins at damage sites $[1,52,84,85]$. Moreover, the concurrent knockdown of RNF20 and SNF2H showed no further reduction of HR frequency than that of a single depletion, indicating epistatic function in the same pathway (Figure 2). Recently, this model of the RNF20-SNF2H chromatin relaxation pathway in DSB repair was elegantly re-confirmed by Klement et al. who showed that RNF20 induces local chromatin relaxation in a SNF2H-dependent manner using a visualized LacR/LacO site-specific heterochromatin relaxation assay [54]. They also showed that the catalytic activity of SNF2H and ATM-mediated phosphorylation sites (S172 and S553) of RNF20 are required for NHEJ at the DSB sites, in which the heterochromatin marker H3K9me3 is localized. ACF1, Lan et al. showed that a binding partner of SNF2H, also has a crucial role in this pathway because the genetic knockdown of ACF1 showed similar phenotypes to that of the SNF2H mutant [52]. Similar results were also reported by Klement et al. who showed that the depletion of SNF2H, ACF1, or RNF20 resulted in the impairment of NCS-induced chromatin relaxation that can be detected by micrococcal nuclease digestion [54]. Therefore, RNF20 and SNF2H function in the same pathway for NHEJ in heterochromatin, although RNF20 seems to have additional roles, including global NHEJ, because knockdown of RNF20 results in the repair defect at a relatively early time point $(6 \mathrm{~h})$, whereas knockdown of SNF2H and ACF1 lead to repair defect only at a later time point (16 h) [54]. This is consistent with the observations by Moyal et al., who showed repair defects in RNF20-depleted cells even at an earlier time point (4 h) [18].

It is obvious that both the RNF20-SNF2H pathway and H2AX pathway depends on ATM because both RNF20/RNF40 and H2AX are phosphorylated with ATM kinase after IR exposure. However, it is noteworthy that the concurrent knockdown of RNF20 and H2AX show additive effects on the reduction of HR repair and enhanced IR sensitivity. Similarly, the depletion of H2AX does not affect IR-induced ubiquitylation of $\mathrm{H} 2 \mathrm{~B}$ and vice versa [1]. This evidence suggested that RNF20/40 and H2AX functions in the distinct pathways of the cellular response to IR. Klement et al. demonstrated that a CHD family remodeling factor CHD3.1 diffused from heterochromatin after IR exposure, and this dispersal is a prerequisite for chromatin remodeling before ATM- and Artemis-dependent DSB repair [54]. Intriguingly, CHD3.1 functions in the same pathway as H2AX, while it is distinct from the RNF20-SNH2H pathway [54,86-89]. Both ACF1.1 and CHD3.1 proteins have a common PHD finger to interact with H3K9me3 [54,90] so that both proteins interact with the same histone marker. Interestingly, CHD3.1 enriched at $\mathrm{H} 3 \mathrm{~K} 9 \mathrm{me} 3$ in heterochromatin was decreased after IR exposure, whereas ACF1.1 was enriched, suggesting a sequential substitution of both proteins at the residue of $\mathrm{H} 3 \mathrm{~K} 9 \mathrm{me} 3$ after IR exposure. Notably, the phosphorylation of $\mathrm{H} 2 \mathrm{AX}$ is a very quick event, whereas the ubiquitylation of $\mathrm{H} 2 \mathrm{~B}$ and accumulation of RNF20 at damaged sites are much slower [1]. The radiation-induced dispersal of CHD3.1 from heterochromatin requires ATM-mediated phosphorylation of KAP-1 (pKAP-1) at S824 [86-88]. This phosphorylation causes the disruption of interactions between SUMOylated KAP-1 and the SUMO-interacting domain of CHD3.1 and thereby detaches from the histone [88]. This dispersal model of CHD3.1 is consistent with the evidence that the NuRD complex containing CHD3.1 participates in the maintenance of transcriptional repression at regions of the genome where DNA is highly methylated and compacted [91]. However, CHD3.1 dispersion is not sufficient for chromatin relaxation, and an 
additional recruitment of SNF2H to DSB sites is also required, particularly in heterochromatin. Although $\mathrm{SNF} 2 \mathrm{H}$ is necessary for chromatin remodeling in both dividing and non-dividing cells, SNF2H is dispensable in dividing CHD3.1-depleted cells. This is because heterochromatic compacting is stably formed in non-dividing cells even after the loss of building factors, whereas dividing cells are unable to form it in the absence of CHD3.1. Thus, decondensing of heterochromatin at DSB sites required two events, in which CHD3.1 initially detaches from H3K9me3 through KAP-1 phosphorylation and SNF2H is subsequently substituted for CHD3.1 at the H3K9me3 site [54].
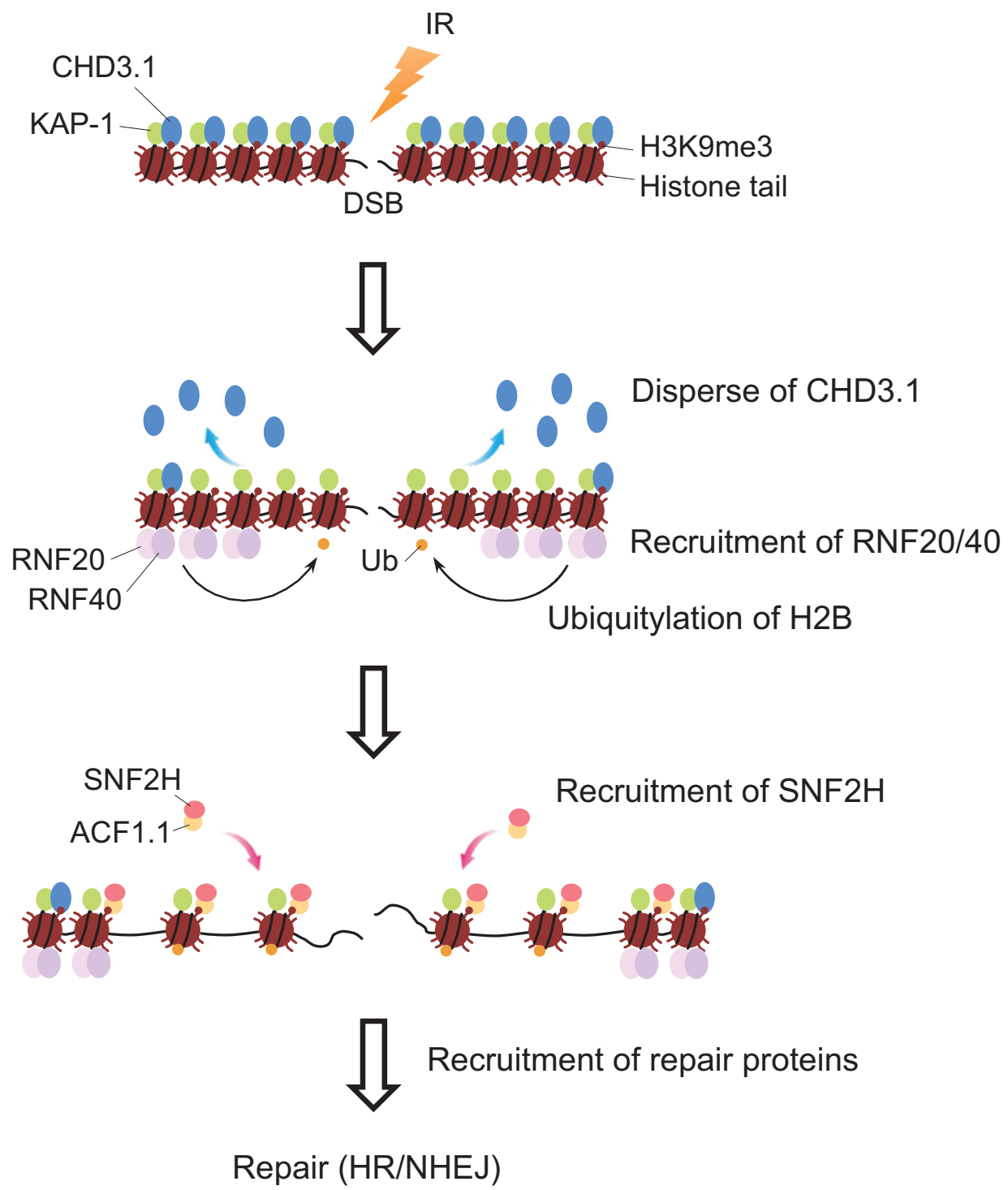

Figure 2. Model of RNF20-SNF2H pathway of chromatin relaxation in DSB repair. Following activation by DSB induction, ATM phosphorylates RNF20 and RNF40. Recruitment of RNF20/40 is carried out via interaction with FACT. Phosphorylated RNF20/40 ubiquitylates H2B at DSB sites. Then, SNF2H is recruited to DSB sites depending on RNF20, SIRT6 and PARP1, and relax compacted chromatin there. Chromatin relaxation by $\mathrm{SNF} 2 \mathrm{H}$ requires prior dispersal of CHD3.1 from damage sites. This event is independent from RNF20 pathway. DNA repair proteins such as BRCA1, RAD51, RPA, XRCC4 are able to access damaged DNA after SNF2H-mediated chromatin remodeling. 
Recruitment of SNF2H to damage sites has been observed at laser-irradiated regions or densely damaged regions by Fok1 nuclease [52,54,82,84,85]. In both systems, the depletion of RNF20 decreases the accumulation of SNF2H, confirming that RNF20 functions upstream of SNF2H at DSB sites $[54,82]$. Laser experimentation also showed that PARP and SIRT6 are implicated in this pathway $[84,85]$; however, it remains inconclusive how these factors are related to each other. Similarly, laser microirradiation revealed that the histone chaperone FACT functions in this pathway as an upstream regulator of RNF20. In transcription, FACT recruits RNF20/40 complex through interaction with PAF1 (RNA polymerase II associated factor) to promote $\mathrm{H} 2 \mathrm{Bub}$-dependent elongation [48]. FACT is a heteromeric dimer of SUPT16H and SSRP1. The depletion of SUPT16H abrogates the accumulation of RNF20 and SNF2H at the damage sites and results in HR defect and hypersensitivity to IR [82,92]. However, RNF20 localization was not affected by PAF1 depletion, even after depletions of ATM and NBS1. Biochemical analysis showed that the RING finger domain at the N-terminus of RNF20 is required for the interaction with the C-terminal region of SUPT16H regardless of transcription, and mutations of this interaction abrogate RNF20 recruitment at the DSB sites. Consequently, RNF20 recruitment to the DSB sites is strongly associated with the activity of the histone chaperone FACT after the generation of DSBs.

\section{Conclusions}

The functional analysis of RNF20 and SNF2H, which had been known in transcription, reveals new roles in chromatin remodeling during DSB repair. From many lines of evidence, the function of RNF20 in DSB repair is mediated by the ubiquitylation of H2B. H2B ubiquitylation and SNF2H appear to sequentially play important roles in ensuring efficient DSB repair. However, how these factors are linked at the molecular level is still unclear. A possible clue that connects these factors directly is histone methylation. It is interesting to note whether H3K9me3-dependent ACF1-SNF2H recruitment would be affected by the H2B ubiquitylation state. The development and analysis of mutants, which harbor a mutation at the ubiquitylation site of $\mathrm{H} 2 \mathrm{~B}$ (K120), may resolve this question. Although there were technical difficulties in achieving this, because the mammalian genome has at least 17 H2B genes [93], the recently developed technologies of genome editing such as CRISPR-Cas9 and TALEN [94-96] would help to overcome this problem in further understanding radiation-induced chromatin reorganization. Since DNA transaction, including transcription and DNA repair, share the common pathway, these mechanical studies would provide useful information in gaining insight into chromatin remodeling in transcription, as well as in DNA repair.

\section{Acknowledgments}

We thank K. Nakamura, D. V. Oliveira and members of the Komatsu laboratory for critical discussion. This work is supported in part by JSPS KAKENHI Grant Numbers 15K00536, and 26241013.

\section{Author Contributions}

Akihiro Kato and Kenshi Komatsu wrote, revised and proofed the manuscript. 


\section{Conflicts of Interest}

The authors declare no conflict of interest.

\section{References}

1. Nakamura, K.; Kato, A.; Kobayashi, J.; Yanagihara, H.; Sakamoto, S.; Oliveira, D.V.N.P.; Shimada, M.; Tauchi, H.; Suzuki, H.; Tashiro, S.; et al. Regulation of homologous recombination by RNF20-dependent H2B ubiquitination. Mol. Cell 2011, 41, 515-528.

2. Kouzarides, T. Chromatin modifications and their function. Cell 2007, 128, 693-705.

3. Shiloh, Y.; Shema, E.; Moyal, L.; Oren, M. RNF20-RNF40: A ubiquitin-driven link between gene expression and the DNA damage response. FEBS Lett. 2011, 585, 2795-2802.

4. Cao, J.; Yan, Q. Histone ubiquitination and deubiquitination in transcription, DNA damage response, and cancer. Front. Oncol. 2012, 2, 1-9.

5. Fuchs, G.; Oren, M. Writing and reading H2B monoubiquitylation. BBA Gene Regul. Mech. 2014, 1839, 694-701.

6. Wood, A.; Krogan, N.J.; Dover, J.; Schneider, J.; Heidt, J.; Boateng, M.A.; Dean, K.; Golshani, A.; Zhang, Y.; Greenblatt, J.F.; et al. Bre1, an E3 ubiquitin ligase required for recruitment and substrate selection of Rad6 at a promoter. Mol. Cell 2003, 11, 267-274.

7. Hwang, W.W.; Venkatasubrahmanyam, S.; Ianculescu, A.G.; Tong, A.; Boone, C.; Madhani, H.D. A conserved RING finger protein required for histone H2B monoubiquitination and cell size control. Mol. Cell 2003, 11, 261-266.

8. Kao, C.F.; Hillyer, C.; Tsukuda, T.; Henry, K.; Berger, S.; Osley, M.A. Rad6 plays a role in transcriptional activation through ubiquitylation of histone H2B. Genes Dev. 2004, 18, 184-195.

9. Kim, J.; Hake, S.B.; Roeder, R.G. The human homolog of yeast BRE1 functions as a transcriptional coactivator through direct activator interactions. Mol. Cell 2005, 20, 759-770.

10. Zhu, B.; Zheng, Y.; Pham, A.D.; Mandal, S.S.; Erdjument-Bromage, H.; Tempst, P.; Reinberg, D. Monoubiquitination of human histone H2B: The factors involved and their roles in HOX gene regulation. Mol. Cell 2005, 20, 601-611.

11. Kim, J.; Guermah, M.; McGinty, R.K.; Lee, J.S.; Tang, Z.; Milne, T.A.; Shilatifard, A.; Muir, T.W.; Roeder, R.G. RAD6-mediated transcription-coupled H2B ubiquitylation directly stimulates H3K4 methylation in human cells. Cell 2009, 137, 459-471.

12. Tanny, J.C.; Erdjument-Bromage, H.; Tempst, P.; Allis, C.D. Ubiquitylation of histone H2B controls RNA polymerase II transcription elongation independently of histone $\mathrm{H} 3$ methylation. Genes Dev. 2007, 21, 835-847.

13. Kim, J.; Roeder, R.G. Direct Bre1-Pafl complex interactions and RING finger-independent Bre1-Rad6 interactions mediate histone H2B ubiquitylation in yeast. J. Biol. Chem. 2009, 284, 20582-20592.

14. Li, X.S.; Trojer, P.; Matsumura, T.; Treisman, J.E.; Tanese, N. Mammalian SWI/SNF-A subunit BAF250/ARID1 is an E3 ubiquitin ligase that targets histone H2B. Mol. Cell. Biol. 2010, 30, $1673-1688$.

15. Minsky, N.; Oren, M. The RING domain of Mdm2 mediates histone ubiquitylation and transcriptional repression. Mol. Cell 2004, 16, 631-639. 
16. Thakar, A.; Parvin, J.D.; Zlatanova, J. BRCA1/BARD1 E3 ubiquitin ligase can modify histones H2A and H2B in the nucleosome particle. J. Biomol. Struct. Dyn. 2010, 27, 399-406.

17. Tweedie-Cullen, R.Y.; Reck, J.M.; Mansuy, I.M. Comprehensive mapping of post-translational modifications on synaptic, nuclear, and histone proteins in the adult mouse brain. J. Proteome Res. 2009, 8, 4966-4982.

18. Moyal, L.; Lerenthal, Y.; Gana-Weisz, M.; Mass, G.; So, S.; Wang, S.Y.; Eppink, B.; Chung, Y.M.; Shalev, G.; Shema, E.; et al. Requirement of ATM-dependent monoubiquitylation of histone H2B for timely repair of DNA double-strand breaks. Mol. Cell 2011, 41, 529-542.

19. Zhang, X.Y.; Varthi, M.; Sykes, S.M.; Phillips, C.; Warzecha, C.; Zhu, W.; Wyce, A.; Thorne, A.W.; Berger, S.L.; McMahon, S.B. The putative cancer stem cell marker USP22 is a subunit of the human SAGA complex required for activated transcription and cell-cycle progression. Mol. Cell 2008, 29, $102-111$.

20. Nicassio, F.; Corrado, N.; Vissers, J.H. A.; Areces, L.B.; Bergink, S.; Marteijn, J.A.; Geverts, B.; Houtsmuller, A.B.; Vermeulen, W.; di Fiore, P.P.; Citterio, E. Human USP3 is a chromatin modifier required for S phase progression and genome stability. Curr. Biol. 2007, 17, 1972-1977.

21. Van der Knaap, J.A.; Kumar, B.R.P.; Moshkin, Y.M.; Langenberg, K.; Krijgsveld, J.; Heck, A.J.R.; Karch, F.; Verrijzer, C.P. GMP synthetase stimulates histone H2B deubiquitylation by the epigenetic silencer USP7. Mol. Cell 2005, 17, 695-707.

22. Joo, H.Y.; Jones, A.; Yang, C.; Zhai, L.; Smith, A.D.; Zhang, Z.; Chandrasekharan, M.B.; Sun, Z.W.; Renfrow, M.B.; Wang, Y.; et al. Regulation of histone H2A and H2B deubiquitination and Xenopus development by USP12 and USP46. J. Biol. Chem. 2011, 286, 7190-7201.

23. Fuchs, G.; Shema, E.; Vesterman, R.; Kotler, E.; Wolchinsky, Z.; Wilder, S.; Golomb, L.; Pribluda, A.; Zhang, F.; Haj-Yahya, M.; et al. RNF20 and USP44 regulate stem cell differentiation by modulating H2B monoubiquitylation. Mol. Cell 2012, 46, 662-673.

24. Zhang, Z.; Jones, A.; Joo, H.Y.; Zhou, D.; Cao, Y.; Chen, S.; Erdjument-Bromage, H.; Renfrow, M.; He, H.; Tempst, P.; et al. USP49 deubiquitinates histone H2B and regulates cotranscriptional pre-mRNA splicing. Genes Dev. 2013, 27, 1581-1595.

25. Henry, K.W.; Wyce, A.; Lo, W.S.; Duggan, L.J.; Emre, N.C.T.; Kao, C.F.; Pillus, L.; Shilatifard, A.; Osley, M.A.; Berger, S.L. Transcriptional activation via sequential histone H2B ubiquitylation and deubiquitylation, mediated by SAGA-associated Ubp8. Genes Dev. 2003, 17, 2648-2663.

26. Emre, N.C.T.; Ingvarsdottir, K.; Wyce, A.; Wood, A.; Krogan, N.J.; Henry, K.W.; Li, K.; Marmorstein, R.; Greenblatt, J.F.; Shilatifard, A.; et al. Maintenance of low histone ubiquitylation by Ubp10 correlates with telomere-proximal Sir2 association and gene silencing. Mol. Cell 2005, 17, 585-594.

27. Metzger, M.B.; Pruneda, J.N.; Klevit, R.E.; Weissman, A.M. RING-type E3 ligases: Master manipulators of E2 ubiquitin-conjugating enzymes and ubiquitination. BBA Mol. Cell Res. 2014, 1843, 47-60.

28. Deshaies, R.J.; Joazeiro, C.A.P. RING Domain E3 Ubiquitin Ligases. Annu. Rev. Biochem. 2009, $78,399-434$.

29. Trujillo, K.M.; Osley, M.A. A role for H2B ubiquitylation in DNA replication. Mol. Cell 2012 , 48, 734-746. 
30. Lin, C.Y.; Wu, M.Y.; Gay, S.; Marjavaara, L.; Lai, M.S.; Hsiao, W.C.; Hung, S.H.; Tseng, H.Y.; Wright, D.E.; Wang, C.Y.; et al. H2B mono-ubiquitylation facilitates fork stalling and recovery during replication stress by coordinating Rad53 activation and chromatin assembly. PLoS Genet. 2014, 10, e1004667.

31. Batta, K.; Zhang, Z.; Yen, K.; Goffman, D.B.; Pugh, B.F. Genome-wide function of H2B ubiquitylation in promoter and genic regions. Genes Dev. 2011, 25, 2254-2265.

32. Latham, J.A.; Chosed, R.J.; Wang, S.; Dent, S.Y.R. Chromatin signaling to kinetochores: Transregulation of Dam1 methylation by histone H2B ubiquitination. Cell 2011, 146, 709-719.

33. Sadeghi, L.; Siggens, L.; Svensson, J.P.; Ekwall, K. Centromeric histone H2B monoubiquitination promotes noncoding transcription and chromatin integrity. Nat. Struct. Mol. Biol. 2014, 21, 236-243.

34. Ma, M.K.W.; Heath, C.; Hair, A.; West, A.G. Histone crosstalk directed by H2B ubiquitination is required for chromatin boundary integrity. PLoS Genet. 2011, 7, e100217516.

35. Pirngruber, J.; Shchebet, A.; Schreiber, L.; Shema, E.; Minsky, N.; Chapman, R.D.; Eick, D.; Aylon, Y.; Oren, M.; Johnsen, S.A. CDK9 directs H2B monoubiquitination and controls replication-dependent histone mRNA 3'-end processing. Nat. Publ. Group 2009, 10, 894-900.

36. Jung, I.; Kim, S.K.; Kim, M.; Han, Y.M.; Kim, Y.S.; Kim, D.; Lee, D. H2B monoubiquitylation is a 5 '-enriched active transcription mark and correlates with exon-intron structure in human cells. Genome Res. 2012, 22, 1026-1035.

37. Vitaliano-Prunier, A.; Babour, A.; Hérissant, L.; Apponi, L.; Margaritis, T.; Holstege, F.C.P.; Corbett, A.H.; Gwizdek, C.; Dargemont, C. H2B ubiquitylation controls the formation of export-competent mRNP. Mol. Cell 2012, 45, 132-139.

38. Buszczak, M.; Paterno, S.; Spradling, A.C. Drosophila stem cells share a common requirement for the histone H2B ubiquitin protease scrawny. Science 2009, 323, 248-251.

39. Karpiuk, O.; Najafova, Z.; Kramer, F.; Hennion, M.; Galonska, C.; König, A.; Snaidero, N.; Vogel, T.; Shchebet, A.; Begus-Nahrmann, Y.; et al. The histone H2B monoubiquitination regulatory pathway is required for differentiation of multipotent stem cells. Mol. Cell 2012, 46, 705-713.

40. Wright, D.E.; Wang, C.Y.; Kao, C.F. Flickin' the ubiquitin switch: The role of H2B ubiquitylation in development. Epigenetics 2011, 6, 1165-1175.

41. Hwang, W.W.; Madhani, H.D. Nonredundant requirement for multiple histone modifications for the early anaphase release of the mitotic exit regulator Cdc14 from nucleolar chromatin. PLoS Genet. 2009, 5, e1000588.

42. Walter, D.; Matter, A.; Fahrenkrog, B. Bre1p-mediated histone H2B ubiquitylation regulates apoptosis in Saccharomyces cerevisiae. J. Cell Sci. 2010, 123, 1931-1939.

43. Shema, E.; Tirosh, I.; Aylon, Y.; Huang, J.; Ye, C.; Moskovits, N.; Raver-Shapira, N.; Minsky, N.; Pirngruber, J.; Tarcic, G.; et al. The histone H2B-specific ubiquitin ligase RNF20/hBRE1 acts as a putative tumor suppressor through selective regulation of gene expression. Genes Dev. 2008, 22, 2664-2676.

44. Johnsen, S.A. The enigmatic role of H2Bub1 in cancer. FEBS Lett. 2012, 586, 1592-1601.

45. Cole, A.J.; Clifton-Bligh, R.; Marsh, D.J. Histone H2B monoubiquitination: Roles to play in human malignancy. Endocr. Relat.Cancer 2014, 22, T19-T33. 
46. Sarkari, F.; Sanchez-Alcaraz, T.; Wang, S.; Holowaty, M.N.; Sheng, Y.; Frappier, L. EBNA1-mediated recruitment of a histone $\mathrm{H} 2 \mathrm{~B}$ deubiquitylating complex to the Epstein-Barr virus latent origin of DNA replication. PLoS Pathog. 2009, 5, e1000624.

47. Fonseca, G.J.; Thillainadesan, G.; Yousef, A.F.; Ablack, J.N.; Mossman, K.L.; Torchia, J.; Mymryk, J.S. Adenovirus evasion of interferon-mediated innate immunity by direct antagonism of a cellular histone posttranslational modification. Cell Host Microbe 2012, 11, 597-606.

48. Pavri, R.; Zhu, B.; Li, G.; Trojer, P.; Mandal, S.; Shilatifard, A.; Reinberg, D. Histone H2B monoubiquitination functions cooperatively with FACT to regulate elongation by RNA polymerase II. Cell 2006, 125, 703-717.

49. Clapier, C.R.; Cairns, B.R. The biology of chromatin remodeling complexes. Annu. Rev. Biochem. 2009, 78, 273-304.

50. Elfring, L.K.; Deuring, R.; McCallum, C.M.; Peterson, C.L.; Tamkun, J.W. Identification and characterization of Drosophila relatives of the yeast transcriptional activator SNF2/SWI2. Mol. Cell. Biol. 1994, 14, 2225-2234.

51. Erdel, F.; Rippe, K. Chromatin remodelling in mammalian cells by ISWI-type complexes - Where, when and why? FEBS J. 2011, 278, 3608-3618.

52. Lan, L.; Ui, A.; Nakajima, S.; Hatakeyama, K.; Hoshi, M.; Watanabe, R.; Janicki, S.M.; Ogiwara, H.; Kohno, T.; Kanno, S.I.; et al. The ACF1 complex is required for DNA double-strand break repair in human cells. Mol. Cell 2010, 40, 976-987.

53. Erdel, F.; Rippe, K. Binding kinetics of human ISWI chromatin-remodelers to DNA repair sites elucidate their target location mechanism. Nucleus 2011, 2, 105-112.

54. Klement, K.; Luijsterburg, M.S.; Pinder, J.B.; Cena, C.S.; del Nero, V.; Wintersinger, C.M.; Dellaire, G.; van Attikum, H.; Goodarzi, A.A. Opposing ISWI- and CHD-class chromatin remodeling activities orchestrate heterochromatic DNA repair. J. Cell Biol. 2014, 207, 717-733.

55. Xiao, A.; Li, H.; Shechter, D.; Ahn, S.H.; Fabrizio, L.A.; Erdjument-Bromage, H.; Ishibe-Murakami, S.; Wang, B.; Tempst, P.; Hofmann, K.; et al. WSTF regulates the H2A.X DNA damage response via a novel tyrosine kinase activity. Nature 2008, 457, 57-62.

56. Pessina, F.; Lowndes, N.F. The RSF1 histone-remodelling factor facilitates DNA double-strand break repair by recruiting centromeric and fanconi anaemia proteins. PLoS Biol. 2014, 12, e1001856.

57. Collins, N.; Poot, R.A.; Kukimoto, I.; García-Jiménez, C.; Dellaire, G.; Varga-Weisz, P.D. An ACF1-ISWI chromatin-remodeling complex is required for DNA replication through heterochromatin. Nat. Genet. 2002, 32, 627-632.

58. Poot, R.A.; Bozhenok, L.; van den Berg, D.L.C.; Steffensen, S.; Ferreira, F.; Grimaldi, M.; Gilbert, N.; Ferreira, J.; Varga-Weisz, P.D. The Williams syndrome transcription factor interacts with PCNA to target chromatin remodelling by ISWI to replication foci. Nat. Cell Biol. 2004, 6, 1236-1244.

59. Patel, D.J.; Wang, Z. Readout of epigenetic modifications. Annu. Rev. Biochem. 2013, 82, 81-118.

60. Horn, P.J.; Peterson, C.L. The bromodomain: A regulator of ATP-dependent chromatin remodeling? Front. Biosci. 2001, 6, D1019-D1023.

61. Zhou, Y.; Grummt, I. The PHD Finger/Bromodomain of NoRC Interacts with Acetylated Histone H4K16 and Is Sufficient for rDNA Silencing. Curr. Biol. 2005, 15, 1434-1438. 
62. Wysocka, J.; Swigut, T.; Xiao, H.; Milne, T.A.; Kwon, S.Y.; Landry, J.; Kauer, M.; Tackett, A.J.; Chait, B.T.; Badenhorst, P.; et al. A PHD finger of NURF couples histone H3 lysine 4 trimethylation with chromatin remodelling. Nature 2006, 442, 86-90.

63. Li, H.; Ilin, S.; Wang, W.; Duncan, E.M.; Wysocka, J.; Allis, C.D.; Patel, D.J. Molecular basis for site-specific read-out of histone H3K4me3 by the BPTF PHD finger of NURF. Nature 2006, 442, 91-95.

64. Ruthenburg, A.J.; Li, H.; Milne, T.A.; Dewell, S.; McGinty, R.K.; Yuen, M.; Ueberheide, B.; Dou, Y.; Muir, T.W.; Patel, D.J.; et al. Recognition of a mononucleosomal histone modification pattern by BPTF via multivalent interactions. Cell 2011, 145, 692-706.

65. Bork, P.; Koonin, E.V. An expanding family of helicases within the "DEAD/H" superfamily. Nucleic Acids Res. 1993, 21, 751-752.

66. Eisen, J.A.; Sweder, K.S.; Hanawalt, P.C. Evolution of the SNF2 family of proteins: Subfamilies with distinct sequences and functions. Nucleic Acids Res. 1995, 23, 2715-2723.

67. Grüne, T.; Brzeski, J.; Eberharter, A.; Clapier, C.R.; Corona, D.F.V.; Becker, P.B.; Müller, C.W. Crystal structure and functional analysis of a nucleosome recognition module of the remodeling factor ISWI. Mol. Cell 2003, 12, 449-460.

68. Dang, W.; Bartholomew, B. Domain architecture of the catalytic subunit in the ISW2-nucleosome complex. Mol. Cell. Biol. 2007, 27, 8306-8317.

69. Narlikar, G.J.; Sundaramoorthy, R.; Owen-Hughes, T. Mechanisms and functions of ATP-dependent chromatin-remodeling enzymes. Cell 2013, 154, 490-503.

70. Mueller-Planitz, F.; Klinker, H.; Becker, P.B. Nucleosome sliding mechanisms: New twists in a looped history. Nat. Struct. Mol. Biol. 2013, 20, 1026-1032.

71. Shiloh, Y. The ATM-mediated DNA-damage response: Taking shape. Trends Biochem. Sci. 2006, 31, 402-410.

72. Matsuoka, S.; Ballif, B.A.; Smogorzewska, A.; McDonald, E.R.; Hurov, K.E.; Luo, J.; Bakalarski, C.E.; Zhao, Z.; Solimini, N.; Lerenthal, Y.; et al. ATM and ATR substrate analysis reveals extensive protein networks responsive to DNA damage. Science 2007, 316, 1160-1166.

73. Uziel, T.; Lerenthal, Y.; Moyal, L.; Andegeko, Y.; Mittelman, L.; Shiloh, Y. Requirement of the MRN complex for ATM activation by DNA damage. EMBO J. 2003, 22, 5612-5621.

74. Lee, J.H.; Paull, T.T. ATM activation by DNA double-strand breaks through the Mre11-Rad50-Nbs 1 complex. Science 2005, 308, 551-554.

75. Tauchi, H.; Kobayashi, J.; Morishima, K.I.; van Gent, D.C.; Shiraishi, T.; Verkaik, N.S.; van Heems, D.; Ito, E.; Nakamura, A.; Sonoda, E.; et al. Nbs1 is essential for DNA repair by homologous recombination in higher vertebrate cells. Nature 2002, 420, 93-98.

76. Xie, A.; Kwok, A.; Scully, R. Role of mammalian Mre11 in classical and alternative nonhomologous end joining. Nat. Struct. Mol. Biol. 2009, 16, 814-818.

77. Game, J.C.; Williamson, M.S.; Spicakova, T.; Brown, J.M. The RAD6/BRE1 histone modification pathway in Saccharomyces confers radiation resistance through a RAD51-dependent process that is independent of RAD18. Genetics 2006, 173, 1951-1968.

78. Yanagihara, H.; Kobayashi, J.; Tateishi, S.; Kato, A.; Matsuura, S.; Tauchi, H.; Yamada, K.; Takezawa, J.; Sugasawa, K.; Masutani, C.; et al. NBS1 recruits RAD18 via a RAD6-like domain and regulates Pol $\eta$-dependent translesion DNA synthesis. Mol. Cell 2011, 43, 788-797. 
79. Falck, J.; Coates, J.; Jackson, S.P. Conserved modes of recruitment of ATM, ATR and DNA-PKcs to sites of DNA damage. Nature 2005, 434, 605-611.

80. Desai-Mehta, A.; Cerosaletti, K.M.; Concannon, P. Distinct functional domains of nibrin mediate Mre11 binding, focus formation, and nuclear localization. Mol. Cell. Biol. 2001, 21, 2184-2191.

81. Chernikova, S.B.; Dorth, J.A.; Razorenova, O.V.; Game, J.C.; Brown, J.M. Deficiency in Bre1 impairs homologous recombination repair and cell cycle checkpoint response to radiation damage in mammalian cells. Radiat. Res. 2010, 174, 558-565.

82. Oliveira, D.V.; Kato, A.; Nakamura, K.; Ikura, T.; Okada, M.; Kobayashi, J.; Yanagihara, H.; Saito, Y.; Tauchi, H.; Komatsu, K. Histone chaperone FACT regulates homologous recombination by chromatin remodeling through interaction with RNF20. J. Cell Sci. 2014, 127, 763-772.

83. Fierz, B.; Chatterjee, C.; McGinty, R.K.; Bar-Dagan, M.; Raleigh, D.P.; Muir, T.W. Histone H2B ubiquitylation disrupts local and higher-order chromatin compaction. Nat. Chem. Biol. 2011, 7, 113-119.

84. Smeenk, G.; Wiegant, W.W.; Marteijn, J.A.; Luijsterburg, M.S.; Sroczynski, N.; Costelloe, T.; Romeijn, R.J.; Pastink, A.; Mailand, N.; Vermeulen, W.; et al. Poly(ADP-ribosyl)ation links the chromatin remodeler SMARCA5/SNF2H to RNF168-dependent DNA damage signaling. J. Cell Sci. 2013, 126, 889-903.

85. Toiber, D.; Erdel, F.; Bouazoune, K.; Silberman, D.M.; Zhong, L.; Mulligan, P.; Sebastian, C.; Cosentino, C.; Martinez-Pastor, B.; Giacosa, S.; et al. SIRT6 recruits SNF2H to DNA break sites, preventing genomic instabilitythrough chromatin remodeling. Mol. Cell 2013, 51, 454-468.

86. Ziv, Y.; Bielopolski, D.; Galanty, Y.; Lukas, C.; Taya, Y.; Schultz, D.C.; Lukas, J.; Bekker-Jensen, S.; Bartek, J.; Shiloh, Y. Chromatin relaxation in response to DNA double-strand breaks is modulated by a novel ATM- and KAP-1 dependent pathway. Nat. Publ. Group 2006, 8, 870-876.

87. Goodarzi, A.A.; Noon, A.T.; Deckbar, D.; Ziv, Y.; Shiloh, Y.; Löbrich, M.; Jeggo, P.A. ATM signaling facilitates repair of DNA double-strand breaks associated with heterochromatin. Mol. Cell 2008, 31, 167-177.

88. Goodarzi, A.A.; Jeggo, P.A. KAP-1 phosphorylation regulates CHD3 nucleosome remodeling during the DNA double-strand break response. Nat. Struct. Mol. Biol. 2011, 18, 831-839.

89. Noon, A.T.; Shibata, A.; Rief, N.; Löbrich, M.; Stewart, G.S.; Jeggo, P.A.; Goodarzi, A.A. 53BP1-dependent robust localized KAP-1 phosphorylation is essential for heterochromatic DNA double-strand break repair. Nat. Publ. Group 2010, 12, 177-184.

90. Musselman, C.A.; Kutateladze, T.G. PHD fingers: Epigenetic effectors and potential drug targets. Mol. Interv. 2009, 9, 314-323.

91. Denslow, S.A.; Wade, P.A. The human Mi-2/NuRD complex and gene regulation. Oncogene 2007, 26, 5433-5438.

92. Kari, V.; Shchebet, A.; Neumann, H.; Johnsen, S.A. The H2B ubiquitin ligase RNF40 cooperates with SUPT16H to induce dynamic changes in chromatin structure during DNA double-strand break repair. Cell Cycle 2011, 10, 3495-3504.

93. Marzluff, W.F.; Gongidi, P.; Woods, K.R.; Jin, J.; Maltais, L.J. The human and mouse replication-dependent histone genes. Genomics 2002, 80, 487-498.

94. Hsu, P.D.; Lander, E.S.; Zhang, F. Development and applications of CRISPR-Cas9 for genome engineering. Cell 2014, 157, 1262-1278. 
95. Wright, D.A.; Li, T.; Yang, B.; Spalding, M.H. TALEN-mediated genome editing: Prospects and perspectives. Biochem. J. 2014, 462, 15-24.

96. Gaj, T.; Gersbach, C.A.; Barbas, C.F., III; ZFN, TALEN, and CRISPR/Cas-based methods for genome engineering. Trends Biotechnol. 2013, 31, 1-9.

(C) 2015 by the authors; licensee MDPI, Basel, Switzerland. This article is an open access article distributed under the terms and conditions of the Creative Commons Attribution license (http://creativecommons.org/licenses/by/4.0/). 